\title{
Mulheres, violência e território: experiências desde Portugal ${ }^{1}$
}

\author{
Women, violence and territory: Portuguese experiences
}

\author{
Lia Pereira Saraiva Gil Antunes ${ }^{2}$ \\ Fecha de recepción: 30-03-2018 - Fecha de aceptación: 04-06-2018 \\ Hábitat y Sociedad (ISSN 2173-125X), n. ${ }^{\circ}$ 11, noviembre de 2018, pp. 149-163. \\ http://dx.doi.org/10.12795/HabitatySociedad.2018.i11.09
}

\begin{abstract}
Urban spaces are, by excellence, places of coexistence, sharing and convergence of diverse realities, which also generate inequalities in access to resources, services and the full enjoyment of social, economic and cultural rights - and the gender issue is transversal-. Feminist territorial strategies intervene in numerous questions that imply with the life of women's diversity, with special attention to security's perceptions and specific violence against women. The forms of intervention are adapted to the context of each place and each community, generating diverse and creative responses. Methodologically, it focuses on the bibliographic and documental review, analysis of statistical data and participant observation of two case studies carried out in Portugal. "The Revolt of the Cloths", in 2016, and "Maps of Violence", in 2017, both in Covilhã, born of horizontal and interdisciplinary feminist activism, organized in sessions of meetings, production and debate, participated mostly by women. These proposals are based on an individual and collective awareness of the reproduction of unbalanced relations of power and the perpetuation of forms of violence against women, proving that the systems of domination and subalternization are repeatedly subtle, hidden by traditions and invisible in the public space.
\end{abstract}

\section{Key words}

Feminism; Women; Violence; Participation; Portugal

\begin{abstract}
Resumo
Os espaços urbanos são, por excelência, lugares de convivência, partilha e convergência de realidades diversas, que geram igualmente desigualdades no acesso aos recursos, aos serviços e ao desfrute pleno dos direitos sociais, econômicos e culturais —sendo a problemática de gênero transversal-. As estratégias feministas sobre o território intervêm em inúmeras problemáticas que implicam com a vida da diversidade das mulheres, com uma atenção especial para as suas percepções sobre a segurança e a natureza das violências específicas de que são alvo. As formas de intervenção são adaptadas ao contexto de cada lugar e de cada comunidade, gerando respostas diversas e criativas. Metodologicamente aplica-se a revisão bibliográfica e documental, análise de dados estatísticos e observação participante de dois estudos de caso em Portugal. A "Revolta dos Panos", em 2016, e os "Mapas da Violência", em 2017, ambos na Covilhã, nascem do ativismo feminista, horizontal e interdisciplinar, organizados em sessões de reunião, produção e debate, participados na sua maioria por mulheres. Estas propostas pautam-se pela tomada de consciência, individual e coletiva, da reprodução de relações desequilibradas de poder e da perpetuação das formas de violência sobre as mulheres, provando que os sistemas de dominação e de subalternização são repetidamente subtis, encobertos por tradições e invisíveis no espaço público.
\end{abstract}

\section{Pallavras-chave}

Feminismo; Mulheres; Violência; Participação; Portugal

1 Texto dedicado a Marielle Franco (1979-2018), mulher brasileira feminista negra favelada bissexual, activista contra a violência de Estado e defensora dos Direitos Humanos, socióloga e vereadora do Rio de Janeiro. Assassinada a tiro nas ruas da própria cidade. 2 Arquitecta y doctoranda en Arquitectura en la Universidad de Coimbra sobre perspectivas feministas en el Urbanismo; co-fundadora de la asociación Mulheres na Arquitectura (Portugal); activista en Guerrilha Feminista (Covilhã). E-mail: liapantunes@gmail. com. 


\section{Introducción}

Desde que existem cidades, as mulheres têm participado na sua construção: projetando estruturas e arquiteturas, desenhando bairros e habitações, mais ou menos informais, e atuando (tantas vezes perifericamente) nas esferas social, cultural e política da vida urbana. Não obstante, hoje não há ainda nem um reconhecimento efetivo das profissionais que se envolvem com as temáticas do território nem uma conformação dos espaços coletivos pensados para a heterogeneidade do grupo das mulheres. A experiência nos espaços urbano e rural das mulheres não é igual à dos homens e a transversalidade de género está presente em todos os âmbitos do fazer e viver o ambiente construído. Também as vivências não são homogéneas para a diversidade da condição feminina; as diferenças acontecem na sobreposição ou interseção de identidades sociais e sistemas relacionados de opressão, discriminação ou dominação. ${ }^{3}$ Todavia, a violência de género é uma realidade comum às raparigas e mulheres, com diferentes formas e intensidades em diferentes lugares físicos e sociais, em espaços domésticos, privados ou públicos. Atenta contra a liberdade e autodeterminação feminina, contribui para a percepção de insegurança das mulheres e para o medo assente na consciência do corpo sexuado (Monteiro y Ferreira, 2016). Tal especificidade, diferente da natureza da violência exercida sobre os homens, não tem encontrado uma atenção e problematização especial no planeamento urbano - seja nas esferas profissional, técnica ou de tomada de decisão. As concepções de segurança focam-se na ocorrência de crimes e descuram as percepções e sentimentos de segurança, também enquanto problema de género. Encará-lo como fenómeno omnipresente nos espaços público, privado e comunitário, exige tanto a recolha de dados estatísticos (tendo presente as dificuldades e invisibilidades relativas a sentimentos de vergonha, culpa, tendência para a normalização e receio de denunciar) e mapeamento de práticas violentas e discriminações como o escrutínio de concepções estereotipadas de mulheres, homens e pessoas não-binárias, e dos respetivos papéis sexuais. Apesar de altamente subjetivo e pessoal, é um problema e um desafio político e público.

\section{Linhas de orientação: Tratados, legislação e dados estatísticos sobre as formas de violência sobre raparigas e mulheres}

A Convenção sobre a Eliminação de Todas as Formas de Violência sobre as Mulheres ${ }^{4}$ é conhecida pela sigla inglesa CEDAW e, informalmente, como Magna Carta dos Direitos das Mulheres (PpDM, 2010). $\mathrm{O}$ importante instrumento internacional em matéria de Direitos $\mathrm{Hu}-$ manos enuncia os direitos de todas as mulheres e raparigas, visa eliminar todas as formas de discriminação contra as mulheres e estabelece, como objetivo último, o alcance da igualdade entre mulheres e homens (PpDM, 2016). Alerta para a necessidade de incluir na designada violência de género ${ }^{5}$ a " $(\ldots)$ violência dirigida contra a mulher pelo facto de ser mulher, e que a afecta de forma desproporcionada. Incluem-se aqui danos ou sofrimentos de índole física, mental ou sexual, as ameaças da prática desses atos, a coação e outras formas de privação da liberdade" (PpDM, 2017c, par. 2). Considera ${ }^{6}$ também que “... a violência de género contra as mulheres é uma forma de, social, 
política e economicamente, manter a subordinação das mulheres face aos homens e de perpetuação dos papéis socialmente estereotipados. A violência contra as mulheres consubstancia-se num obstáculo crítico à igualdade substantiva entre mulheres e homens e ao gozo pleno, pelas mulheres, dos seus direitos humanos" (PpDM, 2017c, par. 3).

A Convenção do Conselho da Europa para a Prevenção e o Combate à Violência Contra as Mulheres e a Violência Doméstica, conhecida como Convenção de Istambul, ${ }^{7}$ é igualmente um Tratado Internacional de Direitos Humanos, em particular das raparigas e mulheres (Conselho da Europa, 2011). Juridicamente vinculativo, contempla padrões mínimos para a prevenção e ação dos Estados sobre este tipo de violências, aborda as causas estruturais da violência contra as mulheres e promove a igualdade entre mulheres e homens (PpDM, 2017a). A Convenção reconhece:

[1] ... a violência contra as mulheres é uma manifestação das relações de poder historicamente desiguais entre mulheres e homens que conduziram à dominação e discriminação contra as mulheres pelos homens, o que as impediu de progredirem plenamente; [2] a natureza estrutural da violência exercida contra as mulheres é baseada no género, e que a violência contra as mulheres é um dos mecanismos sociais cruciais pelo qual as mulheres são forçadas a assumir uma posição de subordinação em relação aos homens; [3] as mulheres e as raparigas estão muitas vezes expostas a formas graves de violência tais como a violência doméstica, o assédio sexual, a violação, o casamento forçado, os chamados «crimes de honra» e a mutilação genital, os quais constituem uma violação grave dos direitos humanos das mulheres e das raparigas e um obstáculo importante à realização da igualdade entre mulheres e homens; [4] as mulheres e raparigas estão expostas a um maior risco de violência de género que os homens (PpDM, 2017a). ${ }^{8}$

Além de aludir para a necessidade de proteção e assistência adequada das vítimas e de considerar o desenvolvimento de medidas legislativas que assegurem os incidentes de violência contra as mulheres, no sentido de criminalização efetiva dos agressores, o Tratado convoca uma intervenção holística na prevenção e combate à violência contra as mulheres. Tal implica a implementação de políticas e estratégias ${ }^{9}$ que visem alcançar a igualdade real entre mulheres e homens; a sua concretização depende de uma verdadeira transformação de oportunidades, de instituições, de sistemas e de práticas profissionais e sociais (PpDM, 2017a).

Em 2017 a Comissão para a Cidadania e Igualdade de Género em Portugal publicou um documento relevante que analisa e sintetiza os diversos indicadores-chave (educação, emprego e desemprego, conciliação entre a vida pessoal, familiar e profissional - usos do tempo, pobreza, poder e tomada de decisão, LGBTI) sobre a igualdade de género no cenário nacional. A tendência da população residente no país (10341 milhões de pessoas em 2015) é no sentido da feminização: $52,6 \%$ (5439 milhões) são mulheres (CIG, 2017, p. 2). Sobre a violência de género, e de acordo com as ocorrências registadas, os dados são claros: as principais vítimas de violência doméstica são mulheres e raparigas e os homens são os indivíduos mais denunciados. O assédio sexual e verbal foi reconhecido na legislação portuguesa em 2015 (Decreto-Lei 83/2015), aquando revisão do artigo $170^{\circ}$ do Código Penal ${ }^{10}$ que incorpora o artigo $40^{\circ}$ da Convenção de Istambul. Não obstante, a
7 A Convenção de Istambul foi assinada a 11 de Maio de 2011 e aprovada na Assembleia da República Portuguesa em 2013 (Resolução da AR nº4/2013, de 21 de Janeiro). Sublinhar que a definição do conceito "Mulheres" (artigo $3^{\circ}$, alínea f) inclui as raparigas com menos de 18 anos de idade e que se adopta a perspectiva das discriminações múltiplas ou interseccional na definição.

8 A Convenção reconhece ainda que “... a violência doméstica afecta desproporcionalmente as mulheres e que os homens podem também ser vítimas de violência doméstica (...) as crianças são vítimas da violência doméstica, inclusivamente como testemunhas de violência no seio da família" (PpDM, 2017a).

9 O Comité para a Eliminação da Discriminação Contra as Mulheres "... analisou o $8^{\circ}$ e $9^{\circ}$ relatórios conjuntos de Portugal (CEDAW/C/PRT/8-9) nas 1337 e $1338^{a}$ reuniões, em 28 de Outubro de 2015 (ver CEDAW/C/SR.1337 e 1338).

A lista de assuntos e perguntas do Comité consta do documento CEDAW/C/PR$\mathrm{T} / \mathrm{Q} / 8-9$ e as respostas do Estado Português constam do documento CEDAW/C/ PRT/Q/8-9/Add.1” (PpDM, 2016).

10 Decreto-Lei 83/2015: "Quem importunar outra pessoa, praticando perante ela atos de carácter exibicionista, formulando propostas de teor sexual ou constrangendo-a a contacto de natureza sexual, é punido com pena de prisão até 1 ano ou com pena de multa até 120 dias, se pena mais grave lhe não couber por força de outra disposição legal" (Assembleia da República, 2015). 
11 "O assédio sexual pode implicar não só agressão (ou tentativa de agressão) e contacto físico não consensual, como também insinuações, comentários, piadas, olhares intimidatórios, convites e propostas de teor sexual que não são desejados por quem os recebe. É uma invasão do espaço privado da pessoa, reduzindo-a a um objecto pronto a usar. Não é um elogio, é humilhação. E isso tem repercussões psicológicas, também elas variáveis"(Duarte, 2017)

12 "Em 2016 foram abertos 733 inquéritos pela prática de crime de importunação sexual, mas pouco se sabe sobre o tipo de comportamentos que resultam em condenações" (Flor, 2017).

13 A "Nova Agenda Urbana - Declaração de Quito sobre Cidades e Assentamentos Humanos Sustentáveis para Todos" resulta da Conferência das Nações Unidas sobre a Habitação e o Desenvolvimento Urbano Sustentável (Habitat III) que aconteceu entre 17 e 20 de Outubro de 2016 em Quito, e foi adoptada a 23 de Dezembro de 2016 em Assembleia-Geral da ONU ( Nações Unidas, 2016).

14 Os esforços vão no sentido de cidades e assentamentos humanos que: “... [alinea c)] Alcancem igualdade de género e empoderem todas as mulheres e meninas, garantindo a participação integral e efetiva de mulheres, direitos iguais em todos os campos, e de liderança em todos os níveis de tomada de decisões, e garantindo oportunidades de emprego decente e remuneração igual para trabalho igual, ou trabalho com remuneração igual a todas as mulheres, assim como prevenindo e eliminando todas as formas de discriminação, violência e assédio contra mulheres e meninas em espaços públicos e privados; [alinea f)] Promovam o planeamento atento às questões etárias e de género e investimentos para mobilidade sustentável, segura e acessível a todos e sistemas de transporte de passageiros e de cargas eficientes na utilização de recursos, que efetivamente conecte pessoas, lugares, bens, serviços e oportunidades económicas” (Nações Unidas, 2016, p. 7). sua desvalorização e ridicularização persiste, o problema, que funciona em diversos patamares de funcionamento, ${ }^{11}$ continua invisível e os dados oficiais (e judiciais) sobre o assunto são escassos. ${ }^{12}$ Segundo Duarte $(2017)$,

O assédio — na rua, nos espaços públicos, no trabalho, na Internet-é simultaneamente um sintoma e um pilar estrutural das sociedades machistas, racistas, transfóbicas e androcêntricas em que vivemos. É uma cultura sistémica e profundamente enraizada (...). Em qualquer situação de assédio, o corpo da mulher é visto como algo que não lhe pertence. Como algo que está ao serviço de outrem, sem desejo sexual e agência sexual próprios (par. 4 y 11).

A definição de habitats seguros e inclusivos, que permitam a concretização plena da cidadania de qualquer pessoa, tem estado presente em debates e resoluções a nível mundial. A Agenda 2030 das Nações Unidas estipula 17 objetivos para o Desenvolvimento Sustentável e dedica o $5^{\circ}$ objetivo à "Igualdade de Género e o empoderamento das mulheres", o $10^{\circ}$ objetivo a "Reduzir as Desigualdades" e o $11^{\circ}$ objetivo a "Cidades e Comunidades Sustentáveis" (PpDM, 2017b). Os desafios são amplos e estendem-se à habitação, transportes e espaços públicos seguros, adequados e com preço acessível —com enfoque especial para as necessidades das pessoas em situação de vulnerabilidade (mulheres, crianças, pessoas com alguma limitação ou condicionante e população idosa)—, e à urbanização inclusiva, participativa e sustentável (UNRIC, 2016). Igualmente, a Nova Agenda Urbana, ${ }^{13}$ enquanto instrumento estratégico da concretização da Agenda 2030, reforça peremptoriamente a sua implementação local. Lança, neste sentido, as linhas de orientação para os modos como se planificam, desenham, financiam, desenvolvem, administram e gerem as cidades e os assentamentos humanos para os próximos anos (cfr. Nações Unidas, 2016, p.3). As diretrizes são claras na defesa de cidades e assentamentos urbanos que promovam a igualdade de género e empoderem as raparigas e mulheres. ${ }^{14}$ Reforçase a visão comum para os territórios urbanos e rurais onde “(...) todas e todos as/os habitantes, sem qualquer discriminação, possam viver e construir cidades justas, seguras, saudáveis, acessíveis, resilientes e sustentáveis" (PpDM, 2017a, p. 3).

\section{Linhas de ação: estratégias e intervenções urbanas feministas}

As estratégias urbanas e urbanísticas desde os Feminismos têm cruzado a transversalidade de género com os territórios e assentamentos humanos —na reflexão, produção e ação (participativa) — com a introdução de outras prioridades e experiências nos vários âmbitos do planeamento urbano. Querem convulsionar os modos como se atua sobre os espaços urbanos e rurais, os bairros, quarteirões, ruas e praças, tornando-os favoráveis às necessidades e ritmos da vida reprodutiva e dos cuidados e às vivências das mulheres e de outros grupos socialmente vulneráveis. Tal compromisso implica tanto o envolvimento efetivo destas populações em todas as fases de desenvolvimento de propostas como a revelação das violências pelas mulheres enquanto, segundo Ana Falú, “(...) expresión del ejercicio de poder sobre sus cuerpos, que se perciben como disponibles, y que adquieren categoría política en las resis- 
tencias a las violencias y las denuncias de las mismas" (Col.lectiu Punt 6, 2016, p. 7). A análise integral dos aspetos sociais, físicos e funcionais que condicionam a percepção da (in)segurança nos espaços domésticos, privados, comunitários e públicos, tem obrigatoriamente de ser feita segundo uma perspetiva de género interseccional. Neste sentido, a ferramenta de auditoria e diagnóstico urbano "Entornos Habitables", publicação do coletivo catalão de mulheres Col.lectiu Punt 6 (2016), considera a segurança das pessoas na habitação e no meio envolvente através de um trabalho conjunto que implica o cruzamento entre pessoal técnico, organizações de mulheres e da sociedade civil e de outras pessoas que trabalhem sobre o território. Porque tais fenómenos de violência limitam os direitos humanos e condicionam o direito à cidade na medida em que afetam a qualidade de vida e a realização de projetos pessoais.

Em Portugal, as formas de violência sobre as mulheres refletem uma sociedade machista e patriarcal, com diferentes escalas de intensidade -desde os feminicídios às formas mais subtis e mascaradas- $\mathrm{O}$ aumento da visibilidade e do debate em torno dos temas da violência, quer doméstica quer de género, quer em espaço privado quer em espaço público, deve-se aos esforços de instituições nacionais e de organizações e associações de mulheres, mais ou menos disseminadas pelo território português, e à paulatina tomada de consciência sobre tais fenómenos.

A Covilhã é uma pequena cidade de montanha, implantada na encosta da Serra da Estrela e situada na Beira Baixa, no interior-centro de Portugal. O motor económico em séculos passados foi a indústria de lanifícios, atualmente centra-se sobretudo no sector terciário e na Universidade pública. As mulheres sempre tiveram um papel relevante na cidade, ainda que invisível, ${ }^{15}$ e exerceram um importante papel na indústria de lanifícios, quer na primeira fase da manufatura (trabalhavam como fiandeiras) quer na etapa industrial e mecânica (sobretudo nos trabalhos de acabamento e revisão dos tecidos como esbicadeiras e metedeiras de fios),${ }^{16}$ funções frequentemente mal remuneradas. ${ }^{17}$ Pode dizer-se: não está longe no tempo o convívio diário com a fome, os abandonos, muitos filhos e filhas, as doenças, as múltiplas crises de quem se acostumou a estar regularmente em crise. Pode dizer-se igualmente: hoje elas vivem outras crises, comuns em tantos aspetos à diversidade das mulheres.

No caso particular da Covilhã, anotam-se sinteticamente algumas especificidades e condicionantes urbanas, que afetam maioritariamente estas duas realidades: o isolamento face aos centros principais, a dura topografia, a particularidade sinuosa da rede viária e rede pedonal, a ausência de transportes públicos de qualidade, a escassez de equipamentos - co-cuidadores e corresponsáveis- de apoio às rotinas familiares e ao envelhecimento da população, ${ }^{18} \mathrm{e}$ o difícil acesso à cultura e ao lazer (quase sempre dependente do automóvel). Adicionalmente, a escassez de reflexão sobre o espaço público coletivo (e, consequentemente, a pouca frequência de pessoas), a falta de praças com vida social efetiva e de parques infantis e a descaracterização do centro histórico, demasiado uni-geracional (habitado maioritariamente por uma população idosa), com o edificado em más condições e sem relação com a parte nova da cidade, complementam a imagem urbana covilhanense. Consequentemente, quando as reflexões urbanas se cruzam com a transversalidade de género e se aplicam a cidades com características similares às supra citadas, assiste-se a uma dupla condicionante:
15 De forma a reverter esta invisibilidade histórica, o Plano Intermunicipal para a Igualdade 2017-2020 (Covilhã, Belmonte e Fundão) lançou o "Galardão de Mulheres Notáveis” em 2017, um contributo tanto para tornar mais visível o papel das mulheres na vida da região como servir de estímulo à sua participação na vida pública. Documento disponível online em: http://www.coolabora.pt/publicacoes/ plano\%20intermunicipal\%20igualdade $\%$ 20F-1.pdf.

16 Algumas chegavam a lugares de influência, como Maria José Quinteiro, operadora de máquinas e uma das primeiras a desempenhar o cargo de dirigente sindical, ainda antes do 25 de Abril na Covilhã (Pereira, 2007, p. 64).

17 As mulheres raramente chefiam ou chefiaram as linhas de produção; o sociólogo Heitor Duarte acrescenta que “... foi sempre uma indústria de salários baixos. Durante o Estado Novo os salários estavam tabulados e a mulher ganhava menos que o homem. As mulheres não podiam trabalhar à noite e só quando, na década de 60 [século XX], começam a faltar homens para o turno da noite, que se recusam a trabalhar por questões salariais, é que começam a meter mulheres para estas funções" (Pereira, 2007, p. 79).

18 Destacar o envelhecimento da população em Portugal (sem o aumento proporcional da qualidade de vida), faixa etária maioritariamente feminina (cerca de dois terços), muitas vezes a viverem sozinhas (Campos, 2017). 
19 As discriminações face ao local de origem referem-se a duas realidades actuais: por um lado, a situação das mulheres covilhanenses face ao cenário nacional, por outro, a presença crescente de estudantes da Universidade da Beira Interior, provenientes sobretudo de Angola, Brasil e Cabo Verde.

20 Relativamente ao associativismo, a Covilhã destaca-se a nível nacional pelo grande número de associações dos âmbitos mais diversos, assumindo um papel preponderante no desenvolvimento cultural, desportivo, económico, recreativo e social da cidade e da região. Não obstante, as associações de mulheres são raras. Tal realidade está associada à insuficiente participação, envolvimento e presença das mulheres covilhanenses na vida da cidade e nas tomadas de decisão.

21 A principal missão é “ (...) contribuir para o desenvolvimento das pessoas, das organizações e do território, através de estratégias inovadoras de promoção da igualdade de oportunidades, da participação cívica, da educação e formação e da inclusão social" e apoia-se em princípios socialmente responsáveis, nomeadamente a promoção da coesão social, a defesa da igualdade de oportunidades, na democracia e participação e na aprendizagem colaborativa" (http://www.coolabora.pt/pt/ pag/sobre_n_s/).

22 O coletivo baseia o seu trabalho na interdisciplinaridade, convocando a sociologia, antropologia, estudos de género, ecologia, psicologia, entre outras áreas do conhecimento.

23 Coordenam o "Gabinete de Apoio a Vítimas de Violência Doméstica" e o "Plano Intermunicipal para a Igualdade 2017 2020" num território alargado (nas cidades Covilhã, Belmonte e Fundão).

24 Artista e investigador em Arte do Departamento de Dibujo da Facultad de Bellas Artes da Universidad del País Vasco (UPV/EHU), esteve na Universidade da Beira Interior (Covilhã) entre Maio e Julho de 2016 ao abrigo do programa de intercâmbio Erasmus+. Este projeto resulta de um trabalho prévio de licenciatura realizado em 2012.

25 A intervenção contou com o apoio da Câmara Municipal da Covilhã e da Universidade da Beira Interior e foi distinguida com menção honrosa na $3^{\mathrm{a}}$ edição do Prémio VIDarte - A arte contra a violência doméstica da Comissão para a Cidadania e Igualdade de Género (CIG) . Os panos voltaram a ser apresentados na inauguração do "Gabinete de Apoio a Vítimas de Violência Doméstica” de Belmonte (7 de Outubro de 2016) e por ocasião do Dia Internacional para a Eliminação da Violência contra as Mulheres (de 21 a 25 de Novembro de 2016).

26 Ver, por exemplo, "Quilt (Kantha)

Art of Bengal” (http://sos-arsenic.net/lovingbengal/quilt.html). por um lado, o desafio da periferia - tanto da região do interior e da pequena cidade em relação ao país como a da periferia dentro do próprio aglomerado urbano- por outro, a questão da marginalidade e invisibilidade das mulheres. Ou seja, trata-se, em grande medida, de uma periferia dentro da periferia. Pode dizer-se: as mulheres no interior de Portugal estão atravessadas sobretudo por opressões de género, classe, território e local de origem. ${ }^{19}$

Face à inexistência de coletivos ${ }^{20}$ que dessem resposta aos problemas que (estruturalmente) afetam a população feminina, nasce a cooperativa Coolabora CRL ${ }^{21}$ em 2008. Este grupo de intervenção social é composto por mulheres ${ }^{22}$ que têm vindo a atuar na questão da violência de género e a desenvolver projetos de cidadania ativa ${ }^{23}$ Por meio de parcerias, procuram desenvolver atividades que, por um lado, empoderem e capacitem as mulheres, por outro, revelem as desigualdades e os micro machismos quotidianos. É neste sentido que surgem os projetos "Revolta dos Panos", em 2016, e "Mapas da Violência", em 2017. Com um background feminista presente em todas as fases do projeto, estas estratégias têm sempre lógicas participativas, horizontais e algo performativas.

A "Revolta dos Panos" é uma proposta artística de Arturo Cancio ${ }^{24}$ em parceria com a Coolabora, ${ }^{25}$ realizada entre Maio e Setembro de 2016. A referência são as tradições do Bangladesh, explanadas no livro "The art of Kanth embroidery" de Nia Zaman: as mulheres têm por costume bordar tapetes, num processo de reciclagem de saris usados mediante a técnica de bordado Khanta ${ }^{26}$ que visa prolongar o uso destes tecidos. Podem ter diversas e renovadas funções, amiúde acontece serem oferendas matrimoniais de mães para filhas; no livro supra citado surge uma fotografia de um tapete com a inscrição $A$ existência da mulher está aos pés do marido, revelando até que ponto as mulheres do Bangladesh incorporam e reproduzem as estruturas de dominação nos seus corpos nos seus trabalhos. Através da manufatura de uma série de panos de cozinha, velhos e usados, com ditos populares, o projeto cria paralelismos com a realidade portuguesa: por um lado, enfatiza as opressões, as violências e os machismos presentes nas expressões tradicionais e na linguagem, por outro, remete para o vínculo histórico (e não biológico) das mulheres com o trabalho doméstico e reprodutivo (não remunerado). A decisão de reutilizar panos de cozinha usados, em substituição dos saris, é justificada pelo desejo de transformar materialmente o objeto bordado, desvinculando-o da sua relação com o corpo e associando-o ao conceito de trabalho. Perante esta nova configuração, o objeto bordado abandona a função doméstica vinculada com o corpo feminino oprimido e converte-se numa bandeira reivindicativa. Dessa forma, o mesmo texto deixa de ser um elemento de encarnação da opressão para se tornar num instrumento de denúncia (Cancio, 2017).

Metodologicamente trabalhou-se com grupos locais, ${ }^{27}$ interessados e heterogéneos (compostos na sua maioria por mulheres, de diversas nacionalidades e idades), num total de aproximadamente 80 pessoas (Figura 1 e Figura 2).

Cada grupo discutiu e elegeu provérbios e ditos populares ${ }^{28}$ pertencentes ao acervo cultural e linguístico beirão e português, posteriormente trabalhados em diversas sessões abertas de costura e bordado (Figura 2).

Durante a união dos panos e a cosedura das frases contrastantes a vermelho (Figura 3), estas reuniões foram essenciais tanto pela produ- 

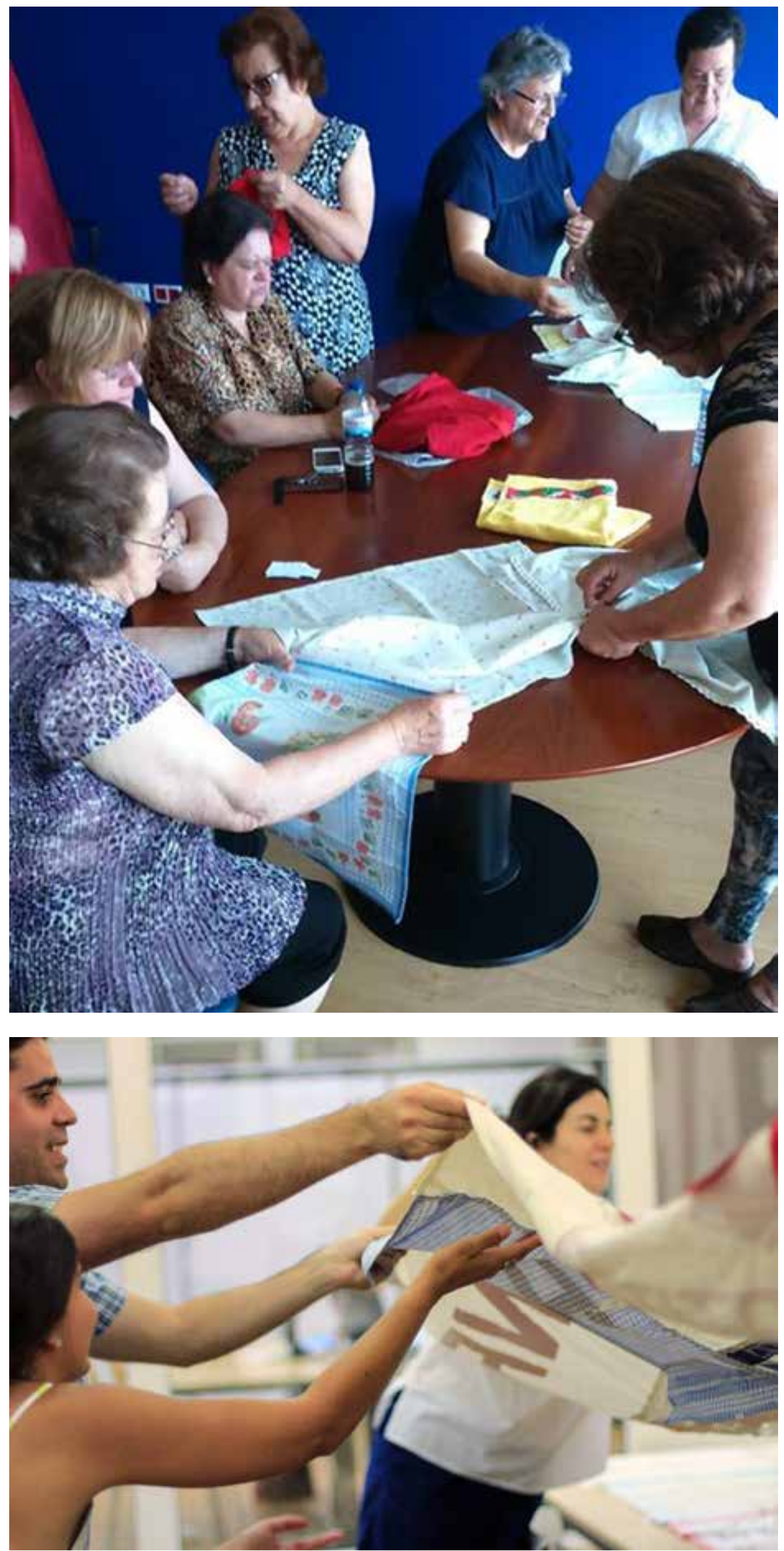

ção das peças como pela geração de momentos íntimos de partilha, de desconstrução, de tomada de consciência individual e de discussão coletiva de um tema frequentemente mascarado de tradição.
Figura 1: Sessão de bordados de grupo de mulheres em Cantar Galo 16 de Julho de 2016). Fonte: Coolabora CRL.

Figura 2: Sessão de bordados na sede da Coolabora (20 de Julho de 2016 ). Fonte: Coolabora CRL.

27 Centro de Convívio e Apoio à Terceira Idade do Tortosendo, União de Reformados e Pensionistas do Tortosendo, Residencial Don António, Lar das Oliveirinhas, Centro Social Santo Aleixo, Associação Mutualista da Covilhã, Clube de Combate e Clube das Ideias.

28 Ditos como "onde há homens não se confessam mulheres", "faça-mas quem mas fizer, quem as paga é a minha mulher", "onde há galo não canta galinha”, "enquanto há homens, não se confessam mulheres", "homem de palha vale mais que mulher de ouro", "cá em casa manda ela, nela mando eu" ou "entre homem e mulher não metas a colher". 
Figura 3: Preparação dos panos e letras de um dos ditos populares (20 de Julho de 2016$)$. Fonte: Coolabora CRL.

Figura 4: Presença do grupo de mulheres participantes do Centro de Convívio e Apoio à $3^{a}$ Idade Tortosendo Os panos ocuparam o Jardim da Covilhã (22 de Setembro de 2016). Fonte: Coolabora CRL.
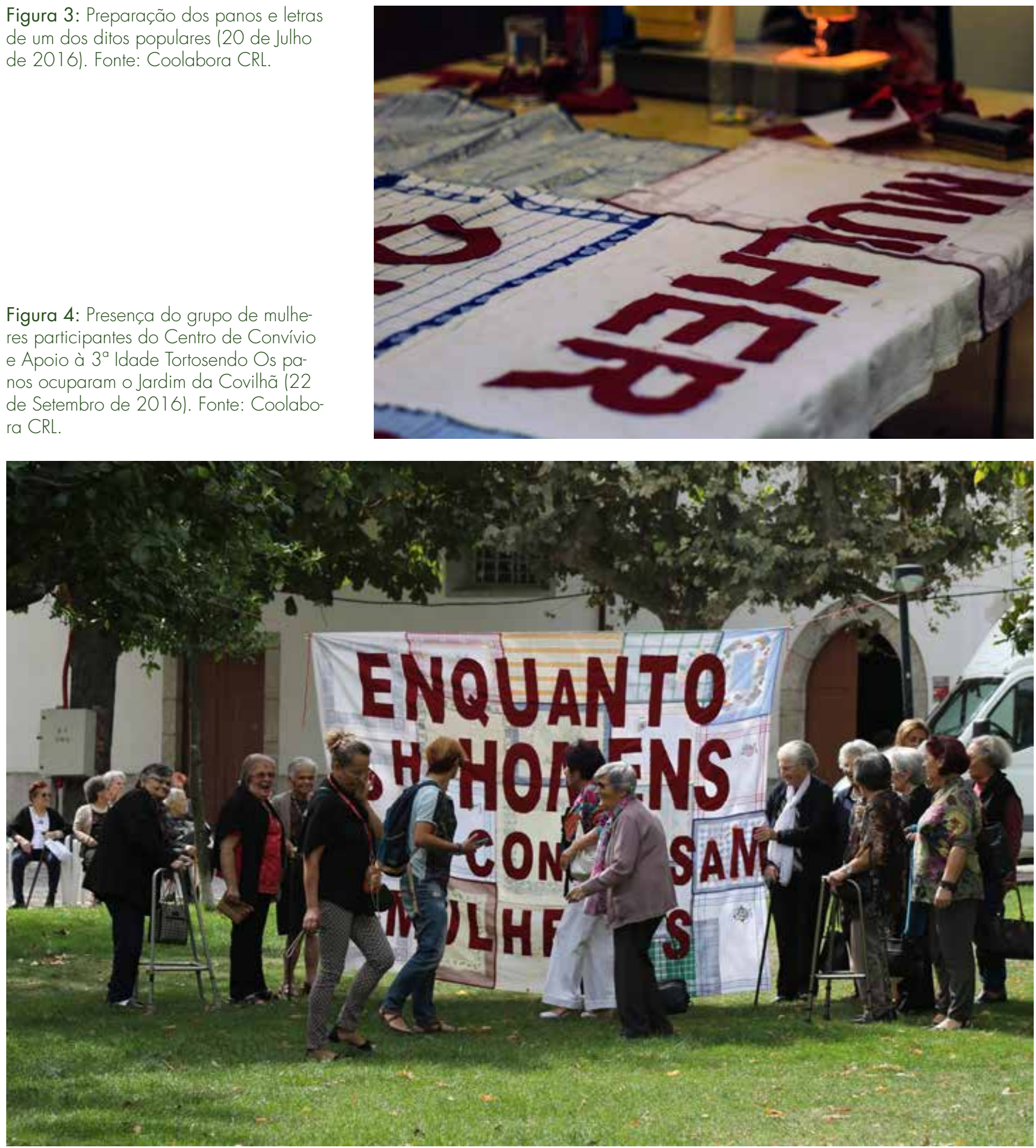

29 Dinamizou-se uma oficina de stencil sobre a violência sexista nas praxes académicas (por Joana Martinho Marques e Lia Antunes), uma oficina Cocina de Guerrilla (por Rúben Castillejo), mostra de videoarte feminista (por Fem Tour Truck), "Poemas à Solta" (por Carmo Póvoas e Sílvia Ferreira), debate "Quem tem medo dos Feminismos?" e concerto participativo e criativo, com sons produzidos por objectos do quotidiano doméstico (dinamizado por Bitocas Fernandes).
Na identificação dos ditos por cada grupo, desvendaram-se mecanismos instalados na linguagem comum, que perpetuam a reprodução de esquemas de dominação, violência e discriminação (Cancio, 2017). O resultado foi a ocupação de um espaço público central, o Jardim Público da cidade, com nove peças finais que alertavam para o potencial inerente à linguagem para influenciar as estruturas e as condições sociais (Cancio, 2017). A apresentação oficial ocorreu durante o festival itinerante de videoarte feminista Fem Tour Truck no dia 22 de Setembro de 2016, num dia preenchido por inúmeras atividades, além da explicação pública do projeto e da colocação dos panos no espaço público ${ }^{29}$ 
(Figura 4 e Figura 5). Os panos transformaram-se em bandeiras de resistência, com capacidade para consciencializar sobre os paradigmas e estereótipos adquiridos e camuflados nas tradições, costumes e na linguagem, que atuam subtilmente e perpetuam a subalternização das mulheres.

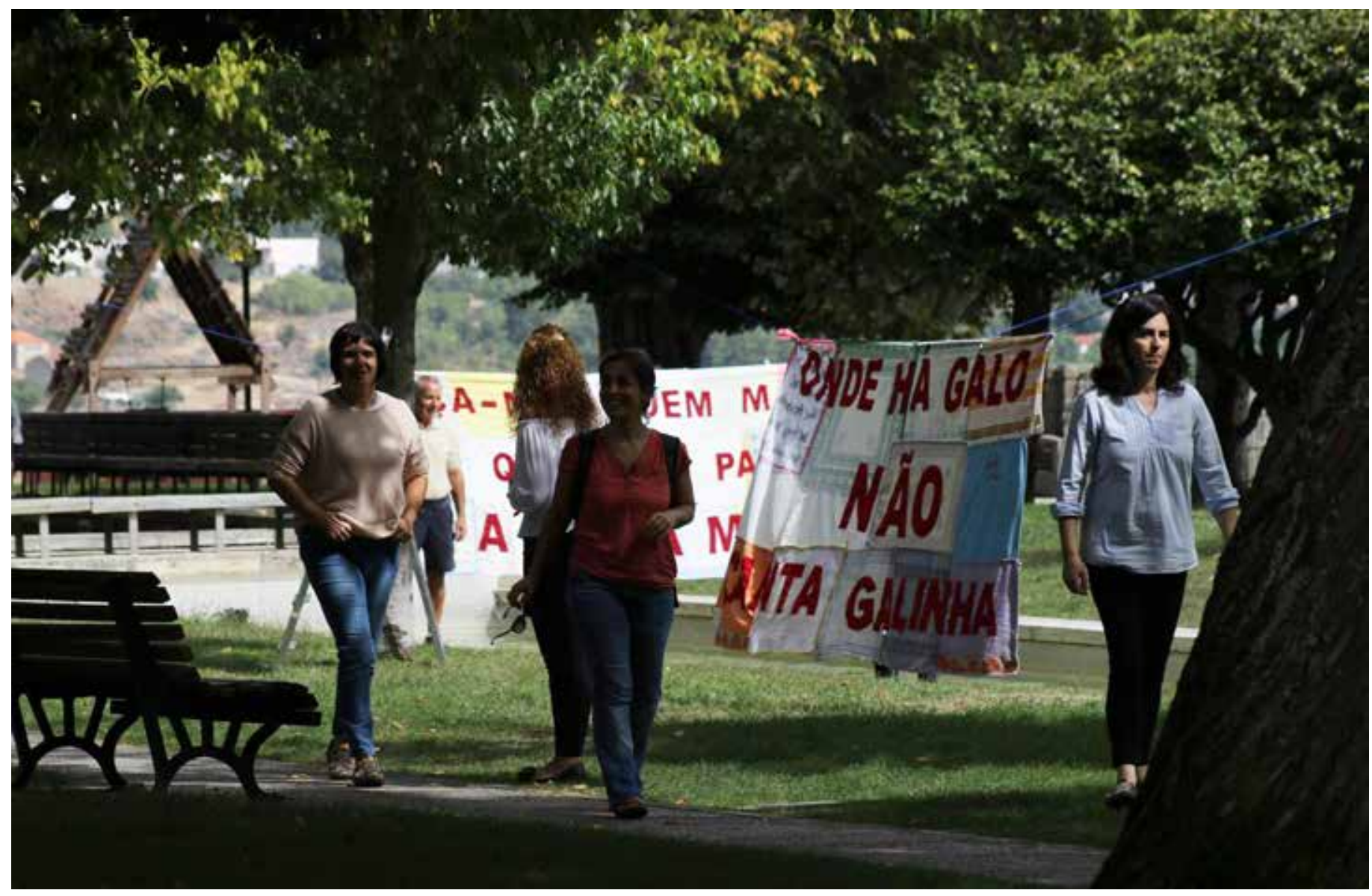

No âmbito do Dia Internacional pela Eliminação de Todas as Formas de Violência sobre as Mulheres, dia 25 de Novembro de 2017, a Coolabora e o coletivo Guerrilha Feminista dinamizaram atividades reivindicativas na Covilhã. O projeto nomeado "Mapas da Violência" desenrolou-se em três momentos: (1) mapeamento das violências, (2) marcha noturna e marcação destes locais, e (3) ocupação do espaço público com performance. O objetivo principal era a denúncia da existência de violência género específica sobre raparigas e mulheres, nos espaços público e privado, sublinhando que tal violência se manifesta de várias formas, que tem histórias reais e locais físicos, que é recorrente durante todas as etapas da vida da população feminina e que acontece tanto nos grandes aglomerados urbanos como nas pequenas e médias cidades, vilas e aldeias. "Mapas da Violência", desenhado por mulheres, desenvolveu-se por etapas que se foram sobrepondo e contaminando. Resultou na recolha de aproximadamente 40 histórias reais de assédio, de agressão física e de femenicídio no espaço público covilhanense, mantidas anónimas e assinadas com o mesmo nome "Maria" (a pensar também na proteção das vítimas), apenas com referência à idade da rapariga ou mulher à data do evento. Durante todo o processo, muitas mulheres, algumas demasiado jovens, confessaram que nunca tinham verbalizado as memórias destes episódios, produzidos tanto pelos companheiros como por sujeitos desconhecidos. Muitas comen-
Figura 5: Nove intervenções, feitas com panos de cozinha usados e marcadas com ditos populares portugueses machistas e sexistas, ocuparam o Jardim público da Covilhã (22 de Setembro de 2016). Fonte: Coolabora CRL. 


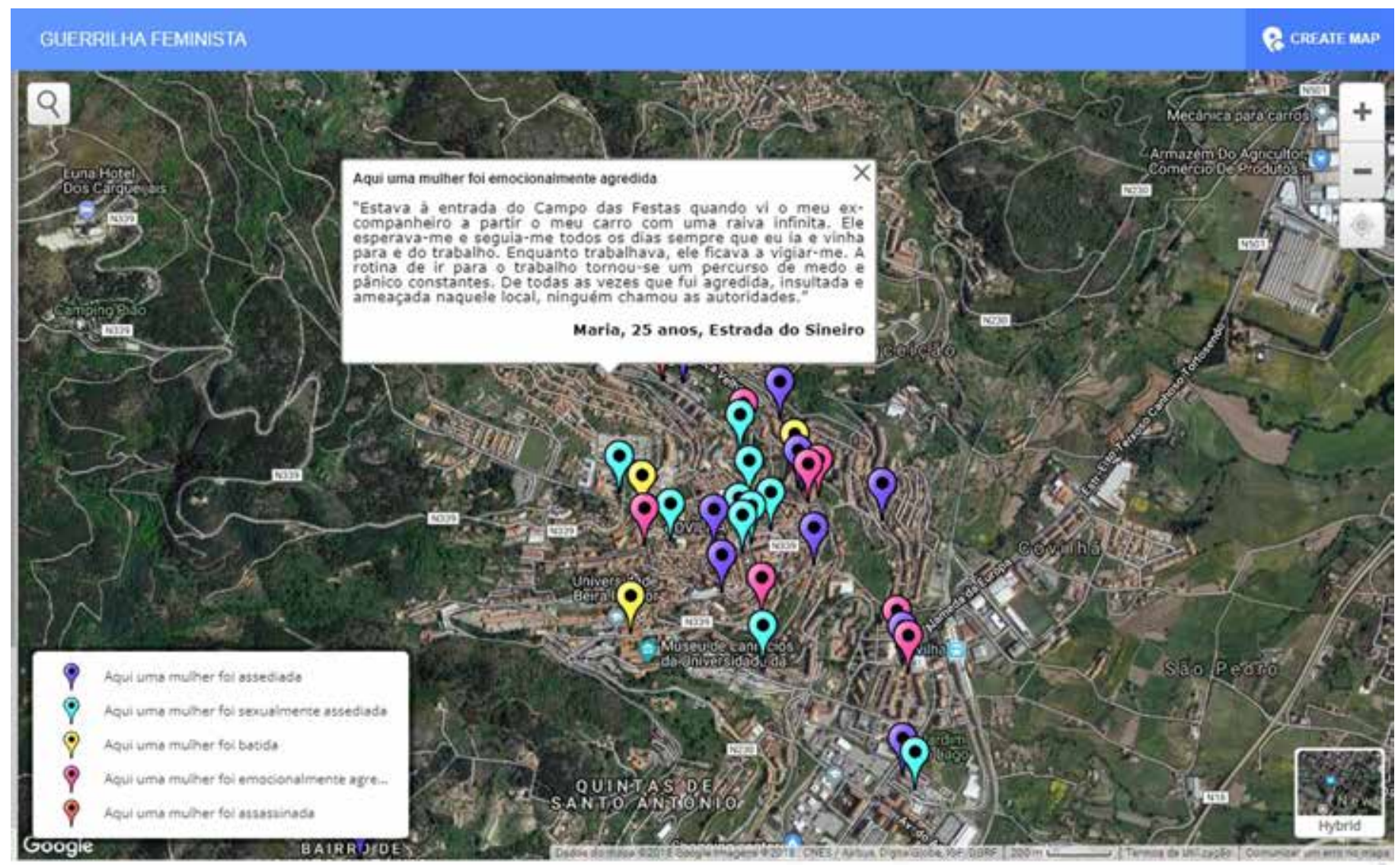

Figura 6: Imagem do mapa online, com legenda /cada legenda/cor corresponde a um tipo de violência sobre as raparigas e mulheres no espaço público) e com a respectiva história. Fonte: https:// www.scribblemaps.com/maps/view/ Guerrilha_Feminista/IZHVLwpcps.
30 O mapa está disponível online, com visualização pública, em https://www.scribblemaps.com/maps/view/Guerrilha_Feminista/lZHVLwpcps. tam a sua falta de reação e de resposta e os consequentes sentimentos de repulsa e de culpa, como se constata nos relatos que se seguem:

Comecei a ter vergonha, comecei a cruzar a rua quando vinha um homem na minha direção, comecei a vestir roupas mais largas, comecei, sem ter consciência, a saber o que era ser mulher nesta sociedade patriarcal. E a arranjar autodefesas na minha própria cidade, cidade esta que me devia cuidar (Maria, entre os 12 e os 15 anos de idade, na Avenida 25 de Abril, Covilhã);

$\mathrm{Ou}$

Porque nós, mulheres, ainda somos vistas como objetos. E, por isso, podemos ser comentadas onde quer que seja e o nosso corpo serve de saco de pancada. E nunca, nunca, importa a roupa que levamos vestida ou a hora a que saímos (Maria, aos 27 anos, na Rua do Castelo, Auditório Municipal, Covilhã) (Guerrilha Feminista y Coolabora CRL, 2017).

Na primeira fase, tais testemunhos foram compilados e georreferenciados num mapa online ${ }^{30}$ (Figura 6), de acordo com uma legenda subdividida em cinco tipos de violência, previamente identificados — "Aqui uma mulher foi assassinada", "Aqui uma mulher foi emocionalmente agredida", "Aqui uma mulher foi batida", "Aqui uma mulher foi sexualmente assediada" e "Aqui uma mulher foi assediada"-, diferenciados com cores distintas.

Após esta etapa, os relatos saíram à rua e foram apresentados num estendal (Figura 7 e Figura 8), agarrados a peças de roupa preta que se pendurou ao longo de um fio vermelho, localizado no Pelourinho, praça central da cidade. A exposição dos testemunhos à comunidade, 
feita pela ocupação deste espaço público com a instalação da roupa e com música cantada por mulheres intercalada por leituras dos mesmos textos, permitiu o intercâmbio (tantas vezes emotivo) pela aproximação a outras mulheres que sentiram as suas experiências representadas.
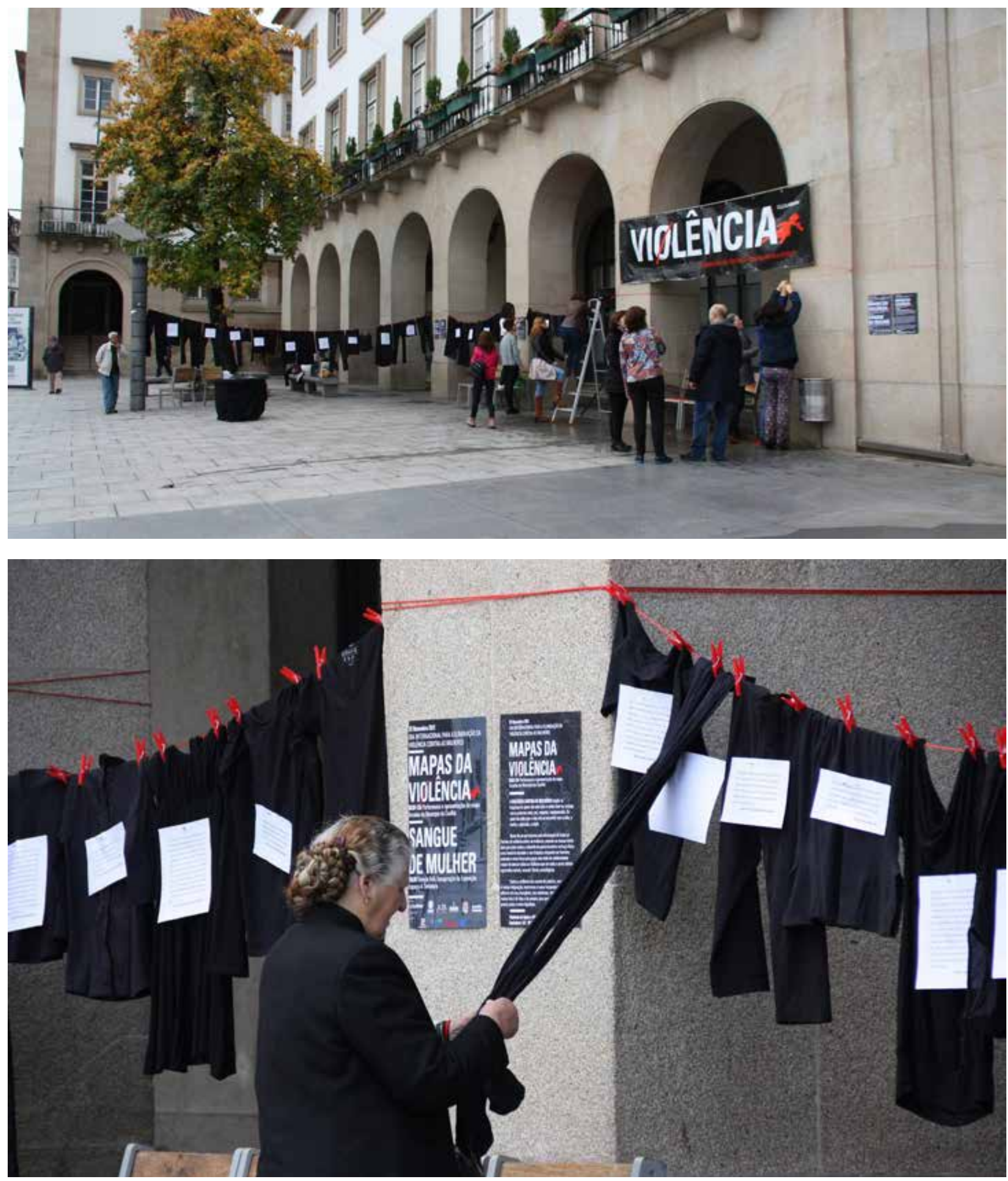

[arriba] Figura 7: $\bigcirc$ estendal com a roupa e as histórias de violência ocuparam as arcadas da Câmara Municipal da Covilhã e a praça central da cidade, Pelourinho (25 de Novembro de 2017). Fonte: Coolabora CRL. [abajo] Figura 8: Mulher em visita à instalação (25 de Novembro de 2017). Fonte: Coolabora CRL. 
Realizou-se igualmente uma marcha noturna, durante a qual se leram as narrativas femininas, em voz alta, e se pintaram as mesmas frases-tipo no pavimento com stencil (Figura 9 e Figura 10). A prova que a visibilidade incomoda foram as tentativas e efetivas supressões de algumas inscrições.
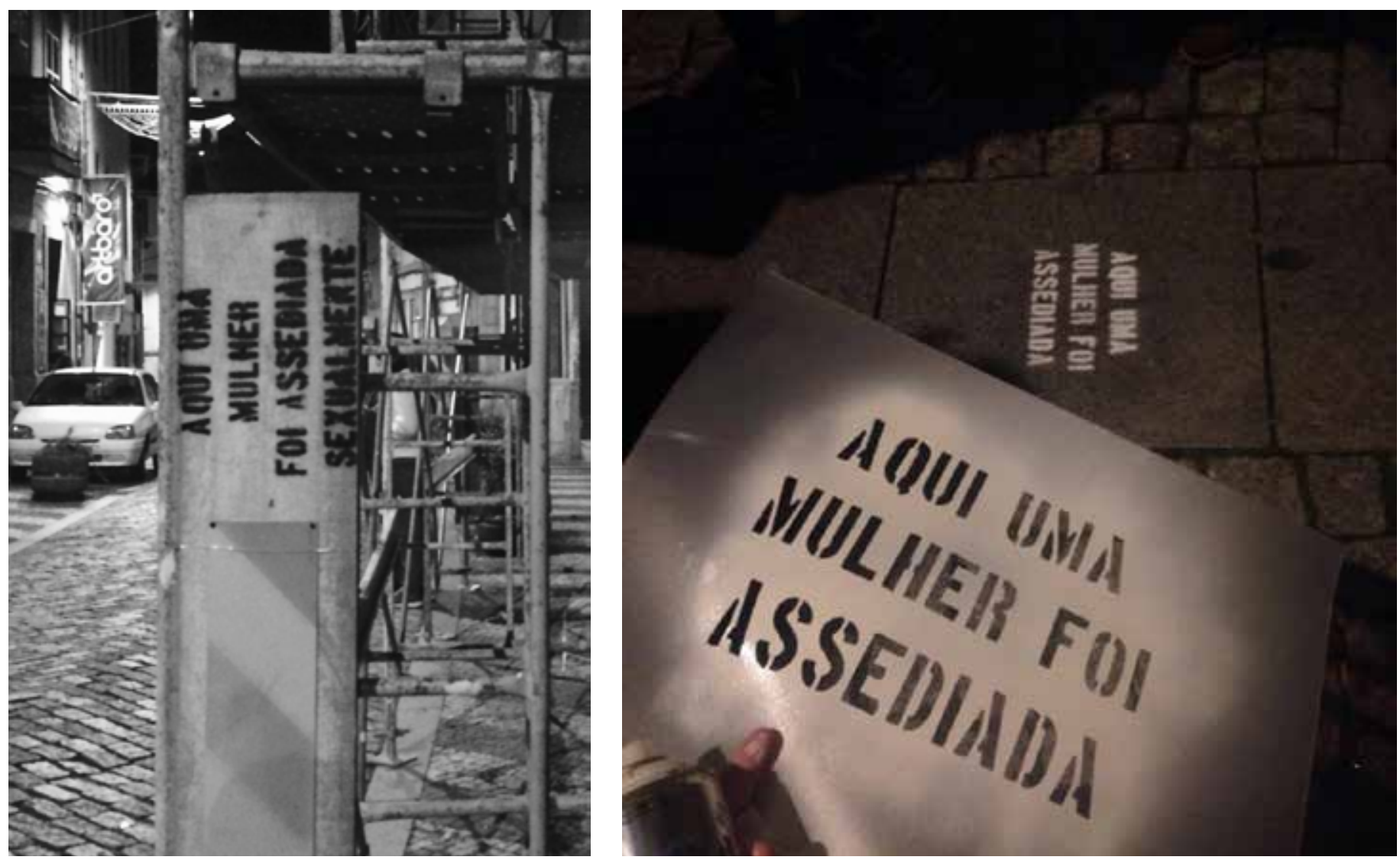

[izquierda] Figura 9: Stencil "Aqui uma mulher foi assediada", pintado no espaço público durante a marcha noturna (24 de Novembro de 2017). Fonte: Coolabora CRL. [derecha] Figura 10: Stencil "Aqui uma mulher foi assediada sexualmente", pintado no espaço público durante a marcha noturna 124 de Novembro de 2017). Fonte: Coolabora CRL.
A cidade acordou marcada, após momentos intensos e íntimos, como uma espécie de cura coletiva entre mulheres. O panfleto, desenhado para o momento, sintetiza bem as ideias chave desta tentativa de escrever pedaços da auto-história das mulheres, para (des)construção das memórias, dos corpos e dos territórios:

As cidades também têm cicatrizes, feridas e memórias infelizes. Se hoje as mapeamos e fazemos o esforço de as desocultar, é para que nos questionemos a partir das ruas, dos jardins e das praças que o nosso quotidiano nos leva a atravessar (...) A violência contra as mulheres expõe as fraquezas de quem não sabe que o verbo viver se conjuga com as palavras amor, paz, respeito, compreensão. De quem não sabe que a vida não se encontra com o ódio, o insulto, a agressão, o medo (...) unamos as nossas vontades para lutar contra a cobardia de quem encontra na força física uma forma de esconder a sua fraqueza enquanto ser humano; usemos a nossa força para gerar uma onda de solidariedade capaz de abarcar todas as mulheres que em toda a parte sofrem agressões verbais, sexuais, físicas, psicológicas. Contra a violência nós usamos da palavra, acrescentamos a nossa indignação, mostramos a nossa humanidade. Contra a violência nós nos insurgimos, nos rebelamos, nos reinventamos. A nossa luta é de hoje e de sempre, para que ao verbo viver se possa juntar o nome dignidade (Coolabora CRL y Guerrilha Feminista, 2017, par. 1, 3 y 4). 
O percurso desenhado pelos "Mapas da Violência" voltou a ser percorrido aquando da iniciativa One Billion Rising Revolution ${ }^{31}$ no dia 19 de Fevereiro de 2018 e a construção do mapa continua em aberto e (infelizmente) em atualização.

\section{Conclusões}

Ambos estudos de caso são ações feministas ${ }^{32}$ de ocupação de espaço público que denunciam e combatem formas particulares de violência sobre raparigas e mulheres. Tratam das suas memórias, da auto-história, individual e coletiva, e do posicionamento (político) do corpo. Num primeiro momento, através da marcação do espaço público com o simbolismo do trabalho reprodutivo e de cuidados e pela desconstrução da linguagem e de provérbios populares portugueses. Depois pela visibilidade de histórias reais de violência pela voz própria de mulheres reais, dando-lhes lugares físicos e relatos verídicos e próximos do contexto que habitamos. Estas propostas tornam-se relevantes e consequentes pela tomada de consciência, individual e coletiva, sobre a reprodução e perpetuação das formas de violência sobre as mulheres, provando que os sistemas de dominação e de subalternização são repetidamente subtis, encobertos por tradições e invisíveis no espaço público. Tais eventos provaram que as violências de género nos lugares coletivos são transversais à diversidade identitária das mulheres em Portugal, desmistificando o foco nos grandes aglomerados urbanos ou em situações familiares e económicas mais desfavorecidas. Sublinham igualmente a objetificação e sexualização do corpo feminino, encarado como mercadoria que pode ser usada e (muitas vezes) abusada. Como comenta Oliveira, o objetivo "(...) não é policiar as relações entre homens e mulheres. É aprender a compartilhar e co-habitar o mundo. O que está em causa é impedir o acesso indesejado ao corpo das mulheres como se fosse propriedade pública"(Duarte, 2017, par. 33).

A exposição contínua a estas experiências tem implicações nas vivências urbanas femininas e influencia os modos como elas se movimentam, de acordo com as perceções de segurança, e como adaptam o medo acumulado ao longo da vida, tantas vezes inconscientemente. Além da importância da educação e cidadania de género, é imperativo ser consequente nesta luta. Por um lado, mudanças efetivas só se alcançarão através dos Feminismos e da associação de mulheres e de outras pessoas implicadas e interessadas. Trabalhar e atuar coletivamente desde os ativismos e das profissões que contribuem para os territórios nas suas diversas escalas e reivindicar um ambiente urbano cuidador e inclusivo. Por outro, pela inclusão das vozes das mulheres e das raparigas em todas as etapas do planeamento urbano e de propostas e pela integração de referentes da população feminina nos quadros de tomada de decisão e de ação sobre as cidades. Realçar, consequentemente, a importância da existência pontual de contextos participativos exclusivos para a diversidade das mulheres, constituídos como espaços de segurança, conforto, e liberdade, que permitam falar pela voz própria. A articulação dos stakeholders - mulheres, organizações, governos e instituições locais, entre outras entidades- pode levar o debate feminista às esferas institucionais e de poder. Porque é de relações (desequilibradas) de autoridade e de poder que se trata. E normalmente o poder nunca é dado, precisa de ser conquistado.
31 One Billion Rising Revolution é uma campanha internacional que começou no dia de 14 de Fevereiro de 2012: "began as a call to action based on the staggering statistic that 1 in 3 women on the planet will be beaten or raped during her lifetime. With the world population at 7 billion, this adds up to more than ONE BILLION WOMEN AND GIRLS" (cfr. https://www.onebillionrising.org/). Desafia as pessoas do mundo inteiro a manifestarem-se pela eliminação da violência contra as mulheres, através de uma dança comum que mostra a força da solidariedade e da resistência colectivas.

32 Apesar do sucesso das iniciativas, de notar a escassez de avaliação das atividades (que permita compreender tanto os aspectos positivos e negativos da sua produção e realização como a efetiva participação da diversidade das mulheres e a disseminação junto da população) e autoavaliação das e dos intervenientes. 
Assembleia da República de Portugal, Lei n. ${ }^{\circ}$ 83/2015, de 05 de Agosto. Lisboa: Assembleia da República de Portugal. Recuperado el 10 de septiembre de 2018, de: http:/ / www.pgdlisboa.pt/leis/lei_mostra_articulado.php? nid=2381 \& tabela $=$ leis\&ficha $=1 \&$ pagina $=1 \&$ sso_miolo $=$.

Campos, A. (2017, 27 de Agosto). População muito idosa duplicou em duas décadas. Público. Recuperado el 08 de agosto de 2018, de: https:/ / www.publico.pt/2017/08/27/sociedade/noticia/populacaomuito-idosa-duplicou-em-duas-decadas-1783479.

Cancio, A. (2017). a revolta dos panos / the revolt of the cloths / бунтът на платовете. En Kieffer, V. (ed.), Niglo - International Art Review, 1, 97-111. Plovdiv: Victoria Kieffer. Recuperado el 08 de agosto de 2028, de: http:/ /victoriakieffer.com/wp-content/uploads/2018/04/ NIGLOAVRIL2018e\%CC\%81cran.pdf.

CIG (2017). Igualdade de Género em Portugal. IndicadoresChave 2017. Lisboa: Comissão para a Cidadania e Igualdade de Género. Recuperado el 16 de febrero de 2018, de: https://www.cig.gov.pt/wp-content/ uploads/2017/07/AF_CIG_FactSheet.pdf.

Col.lectiu Punt 6 (2016). Entornos Habitables. Auditóría de seguridad urbana con perspectiva de género en la vivienda y el entorno. Barcelona: Col.lectiu Punt 6.

Conselho da Europa (2011). Convenção do Conselho da Europa para a Prevenção e o Combate à Violência Contra as Mulheres e a Violência Doméstica (Convenção de Istambul). Estambul: Conselho da Europa. Recuperado el 16 de febrero de 2018, de: https:/ / rm.coe. int/168046253d.

Coolabora CRL y Guerrilha Feminista (2017, 25 de noviembre). Dia Internacional para a Eliminação da Violência Contra as Mulheres. Covilhã: Coolabora, CRL - Intervenção Social. Recuperado el 14 de enero de 2018, de: http://www.coolabora.pt/pt/evento/192.

Crenshaw, K. (1989). Demarginalizing the Intersection of Race and Sex: A Black Feminist Critique of Antidiscrimination Doctrine, Feminist Theory and Antiracist Politics. University of Chicago Legal Forum, 1989(1, Article 8). Recuperado el 06 de agosto de 2018, de: http://chicagounbound.uchicago.edu/ uclf/vol1989/iss $1 / 8$.

Duarte, M. (2017, 3 de diciembre). Assédio Sexual. O Feminismo é para toda a gente. Público. Recuperado el 06 de agosto de 20180, de: https://www.publico.pt/2017/12/03/sociedade/noticia/o-feminismo-e-para-toda-a-gente-1794481.

Flor, A. (2017, 3 de noviembre). Importunação sexual gera dois inquéritos por dia, mas assédio vai além disso. Público. Recuperado el 10 de septiembre de 2018, de: https://www.publico.pt/2017/11/03/sociedade/noticia/importunacao-sexual-gera-dois-inqueritos-por-dia-mas-assedio-vai-alem-disso-1791206.

Guerrilha Feminista y Coolabora CRL. (2017, 25 de noviembre). Mapas da Violência [Recurso online]. Recuperado el 25 de Novembro de 2017, de: https://www.scribblemaps.com/maps/view/Guerrilha_Feminista/1ZHVLwpcps.

Monteiro, R. y Ferreira, V. (eds.) (2016). Guia para a Integração a Nível Local da Perspetiva de Género na Segurança e Prevenção da Violênica no Espaço Público. Coimbra: CES - Centro de Estudo Sociais da Universidade de Coimbra.

Nações Unidas (2016). Nova Agenda Urbana (Habitat III). Quito: Nações Unidas. Recuperado el 08 de agosto de 2018, de: http:/ / habitat3.org/wp-content/uploads/NUA-Portuguese-Angola.pdf.

Pereira, A. C. (2007). Estudo do Tecido Operário Têxtil da Cova da Beira. Covilhã: Sindicato dos Trabalhadores do Sector Têxtil da Beira Baixa.

PpDM (2010). CEDAW. A Magna Carta dos Direitos das Mulheres. Lisboa: Plataforma Portuguesa pelos Direitos das Mulheres. Recuperado el 15 de febrero de 2018, de: http:/ / plataformamulheres.org.pt/wp-content/ficheiros/ppdm-encarte-WEB.pdf.

PpDM (2016). Convenção sobre a Eliminação de Todas as Formas de Discriminação Contra as Mulheres (CEDAW). O Estado da Arte em Portugal. Lisboa: Plataforma Portuguesa pelos Direitos das Mulheres.

PpDM (2017a). Convenção do Conselho da Europa para a Prevenção e o Combate à Violência Contra as Mulheres $e$ a Violência Doméstica. Convenção de Istambul. Lisboa: Plataforma Portuguesa pelos Direitos das Mulheres.

PpDM (2017b). Integração da Dimensão da Igualdade de Género na Nova Agenda Urbana. Lisboa: Plataforma Portuguesa pelos Direitos das Mulheres.

PpDM (2017c, 13 de Septiembre). É tempo para irmos das palavras à ação: Tolerância zero à violência contra as mulheres e as raparigas. [Entrada de blog] Plataforma portuguesa para os Direitos das Mulheres. Recuperado el 15 de febrero de 2018, de: http:/ / plataformamulheres.org.pt/e-tempo-para-irmosdas-palavras-a-acao-tolerancia-zero-a-violencia-contra-as-mulheres-e-as-raparigas /.

UNRIC - Centro Regional de Informação das Nações Unidas para a Europa Ocidental (2016). 17 Objetivos de Desenvolvimento Sustentável da Agenda 2030. Recuperado el 22 de febrero de 2018, de: https:/ / www.unric.org/pt/17-objetivos-de-desenvolvimentosustentavel. 
Pereira Saraiva Gil Antunes, L. (2018). Mulheres, violência e território: experiências desde Portugal. Hábitat y Sociedad, 11, 149163.

<http://dx.doi.org/10.12795/HabitatySociedad.2018.i11.09>

$\bigcirc$ 


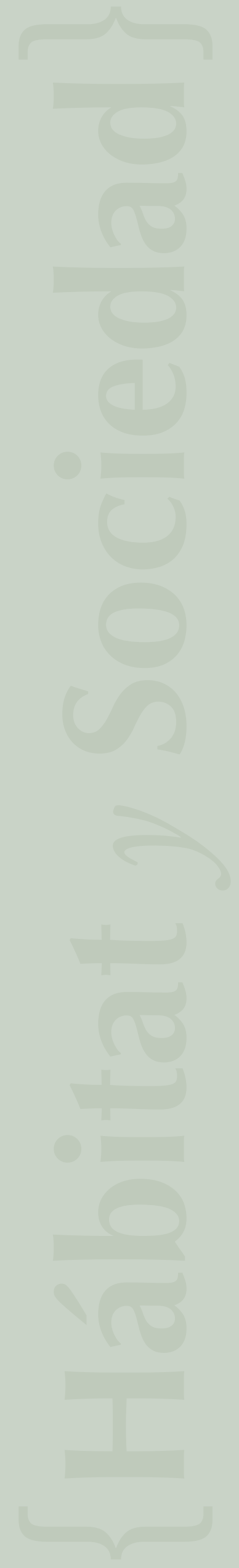

